\title{
Effect of the presence of coexisting substances on UV inactivation of Cryptosporidium parvum oocysts
}

\author{
Shigemitsu MORITA*1 and Tsuyoshi HIRATA*1 \\ *1 School of Environmental Health, Azabu University, 1-17-71 Fuchinobe, Sagamihara, \\ Kanagawa 229-8501, Japan (E-mail: moritas@azabu-u.ac.jp, hiratat@azabu-u.ac.jp)
}

\begin{abstract}
Three turbid substances were added to suspensions of Cryptosporidium parvum oocysts, and changes in the degree of ultraviolet (UV) inactivation of the C. parvum oocysts were evaluated by in vitro excystation and animal infectivity. Because the dose distribution of UV irradiation delivered to oocysts in turbid water may vary according to the degree of movement of the water, experiments were performed under vigorously mixed (completely mixed) conditions and stationary conditions. The estimated kinetic inactivation rate in the completely mixed system of turbid water (190 ntu) was $4.058 \mathrm{~cm}^{2} / \mathrm{mJ}$, which was only $15 \%$ less than that in pure water $\left(4.690 \mathrm{~cm}^{2} / \mathrm{mJ}\right)$. The estimated relative infectivity in the stationary system differed markedly from that obtained by regression of the plot of UV irradiation dose versus relative infectivity in pure water. Nevertheless, values of the relative infectivity obtained in animal experiments were nearly in agreement with the calculated values. In other words, despite decreases in the dose of UV delivered to oocysts under the influence of turbid substances, the efficacy of UV in inactivation of oocysts in turbid water was almost equal to that in pure water when expressed as per unit dose. Consequently, it became evident consequently that if the dose of UV delivered to oocysts was known, the degree of expected inactivation could be estimated. In addition, we added substances that adhere to the surface of $C$. parvum oocysts (humin and kaoline) to suspensions of $C$. parvum oocysts and studied the degree of UV inactivation. Adhesion of humin or kaoline particles to the oocyst wall resulted in a reduction in UV inactivation. However, the magnitude of the $\log _{10}$ inactivation in a suspension containing humin or kaoline particles was only about $20 \%$ and $10 \%$, respectively, less than that in pure water.
\end{abstract}

\section{KEYWORDS}

Cryptosporidium parvum, Ultraviolet, Inactivation, Coexisting substances, Adherent substances

\section{INTRODUCTION}

Cryptosporidiosis outbreaks arising from contaminated surface water supplies have been documented in many countries (Mackenzie et al., 1994, Atherton et al., 1995, Yamamoto et al., 2000). It is believed that Cryptosporidium parvum oocysts are widespread in rivers; the concentration of $C$. parvum oocysts in source river waters is as high as $10^{4}$ oocysts/100 L (Rose et al., 1991, LeChevallier et al., 1991). Although coagulation-sedimentation and rapid sand filtration can reduce the number of $C$. parvum oocysts by 2 to $4 \log$ (Nieminski et al., 1995, Baudin and Laine, 1998, Hashimoto et al., 2002), the expected rate of removal may not be sufficient to reduce the risk of infection to an acceptable level in cases where the source water is strongly contaminated with $C$. parvum oocysts. Chlorine has been used as a final disinfectant in many water supplies; however, $C$. parvum oocysts are insensitive to chlorine at the concentrations routinely used (Korich et al, 1990, Gyurek et al, 1997, Hirata et al, 2000) and thus there is interest in developing an alternative and more effective disinfectant for inactivating such recalcitrant microorganisms.

Ultraviolet (UV) disinfection systems produce no hazardous by-products and are easy to maintain. UV irradiation is considered to be one of the more effective techniques for inactivating bacteria and viruses (Sobsey, 1989). Fewer studies have been conducted on the effects of UV irradiation on $C$. parvum than on bacteria and viruses because UV irradiation was not considered to be effective in inactivating C. parvum based on results of in vitro excystation (Ransome et al., 1993). However, there is substantial evidence suggesting that UV irradiation at low doses can reduce the infectivity of C. parvum oocysts (Linden et al., 2000, Clancy et al., 2000, Shin et al., 2001, Morita et al., 2002, 
Zimmer et al., 2003).

One problem that needs to be addressed before adopting UV irradiation as a method for disinfecting water is the reduction in UV irradiation efficacy caused by the presence of turbid substances in water (Hirata et al., 2002). In particular, substances that tend to adhere to the surface of C. parvum oocysts may reduce the effectiveness of disinfectants.

Therefore, in this study, we examined the effects of turbid substances in suspensions of C. parvum oocysts on the degree of UV inactivation of the oocysts using the animal infectivity assay. In addition, we evaluated the effects of humin or kaoline, which adhere to the surface of C. parvum oocysts, on the degree of UV inactivation of $C$. parvum oocysts using in vitro excystation and animal infectivity assays.

\section{MATERIALS AND METHODS}

\section{Cryptosporidium parvum oocysts}

The C. parvum HNJ-1 strain (human isolate by Dr. Iseki, Kanazawa University, Japan) that was passaged in SCID mice (C.B-17/Icr, CLEA Japan Inc, Tokyo, Japan) at the Research Institute of Biosciences, Azabu University, was used for this study. Fresh feces from several infected mice was placed in $500 \mathrm{~mL}$ of purified water, emulsified, and filtered through a $0.1-\mathrm{mm}$ mesh nylon sieve. A filtrate containing $C$. parvum oocysts was obtained. The crude oocyst suspension $(20 \mathrm{~mL})$ was underlaid with sucrose solution (specific gravity of 1.100 at $20^{\circ} \mathrm{C}$ ) and centrifuged at $1,500 \times \mathrm{g}$ at 4 ${ }^{\circ} \mathrm{C}$ for 15 minutes. The interface and upper layer were recovered, and diluted with $150 \mathrm{mM}$ of $\mathrm{pH}$ 7.4 phosphate-buffered saline (PBS; $0.20 \mathrm{~g}$ of potassium dihydrogen phosphate, $0.20 \mathrm{~g}$ of potassium chloride, $1.15 \mathrm{~g}$ of disodium hydrogen phosphate and $8.0 \mathrm{~g}$ of sodium chloride in 1 liter of distilled water) containing $0.1 \%(\mathrm{~V} / \mathrm{v})$ Tween 80 . The diluted solution was centrifuged at $1,500 \times \mathrm{g}$ at $4{ }^{\circ} \mathrm{C}$ for 15 minutes. The precipitate was then diluted to $20 \mathrm{~mL}$ with PBS containing $0.1 \%(\mathrm{~V} / \mathrm{v})$ Tween 80 . The suspension was underlaid with sucrose solution and centrifuged at $1,500 \times g$ at $4{ }^{\circ} \mathrm{C}$ for 15 minutes. The interface was recovered. Washing with PBS containing $0.1 \%(\mathrm{v} / \mathrm{v})$ Tween 80 was performed four times in order to remove fecal matter. The stock of purified oocysts was stored in PBS at $4{ }^{\circ} \mathrm{C}$ and was used in experiments within 7 days.

\section{UV irradiation of $C$. parvum oocysts in the presence of various substances}

Three substances were added to suspensions of $C$. parvum oocysts and the efficacy of UV irradiation in inactivating the oocysts was studied. Substances added and conditions of UV irradiation in each of the 13 experiments are shown in Table 1.

Table 1. Substances that were placed in suspensions of C. parvum oocysts and conditions of UV irradiation.

\begin{tabular}{|c|c|c|c|c|c|c|c|}
\hline \multirow{2}{*}{ Run } & \multirow{2}{*}{ Added substance } & \multirow{2}{*}{$\begin{array}{l}\text { Condition of added } \\
\text { substance }\end{array}$} & \multirow{2}{*}{ Mixing system } & \multirow{2}{*}{$\begin{array}{c}\text { Intensity** } \\
\left(\mathrm{mW} / \mathrm{cm}^{2}\right)\end{array}$} & \multirow{2}{*}{$\begin{array}{l}\text { Time } \\
(\mathrm{s})\end{array}$} & \multicolumn{2}{|c|}{ Dose $\left(\mathrm{mJ} / \mathrm{cm}^{2}\right)$} \\
\hline & & & & & & Surface*** & Average $* * * *$ \\
\hline 1 & \multirow{4}{*}{ Pure water } & & completely mixed & 0.10 & 5 & 0.5 & 0.5 \\
\hline 2 & & & completely mixed & 0.10 & 10 & 1.1 & 1.1 \\
\hline 3 & & & completely mixed & 0.10 & 15 & 1.5 & 1.5 \\
\hline 4 & & & completely mixed & 0.10 & 20 & 2.1 & 2.1 \\
\hline 5 & \multirow{4}{*}{$\begin{array}{l}\text { Concentrated } \\
\text { substances from river } \\
\text { water* }\end{array}$} & suspended uniformly & completely mixed & 0.10 & 30 & 3.0 & 1.0 \\
\hline 6 & & suspended uniformly & completely mixed & 0.10 & 60 & 6.0 & 2.1 \\
\hline 7 & & suspended uniformly & completely stationary & 1.00 & 3 & 3.0 & 1.1 \\
\hline 8 & & suspended uniformly & completely stationary & 1.00 & 6 & 6.0 & 2.3 \\
\hline 9 & \multirow{3}{*}{ Humin } & dissolved & completely mixed & 0.20 & 77 & 15.4 & 1.5 \\
\hline 10 & & suspended uniformly & completely mixed & 0.20 & 37 & 7.4 & 1.5 \\
\hline 11 & & adhered to oocysts & completely mixed & 0.20 & 36 & 7.2 & 1.5 \\
\hline 12 & \multirow{2}{*}{ Kaoline } & suspended uniformly & completely mixed & 0.10 & 42 & 4.2 & 1.5 \\
\hline 13 & & adhered to oocysts & completely mixed & 0.10 & 36 & 3.6 & 1.5 \\
\hline & \multicolumn{7}{|c|}{$\begin{array}{l}* \text { Concentrated with ultra-filtration membranes } \\
* * \text { UV intensity at the surface of the suspension } \\
* * * \text { UV dose at the surface of the suspension } \\
* * * * \text { Average UV dose from the surface to the bottom }\end{array}$} \\
\hline
\end{tabular}


Turbid substances in river water were concentrated using hollow-fiber ultra-filtration (UF) membranes (90\% cut off: 150,000 daltons; Daicen Membrane-Systems, Ltd., Osaka, Japan). The turbid substances were removed from the surface of the UF membranes by shaking with sterilized tap water. The removed substances were sterilized by chlorination (at 3,000 $\mathrm{mg} / \mathrm{L}$ for 5 minutes) followed by UV irradiation (over $20 \mathrm{~J} / \mathrm{cm}^{2}$ ) and were then diluted with sterilized tap water to 190 ntu. The turbidity of the suspension was determined by measuring the absorbance at $660 \mathrm{~nm}$ with a spectrophotometer (UV-150-2; Shimadzu Co., Tokyo, Japan). A purified suspension of C. parvum oocysts was placed into an open plastic tube with an inner diameter of $36 \mathrm{~mm}$ containing $30 \mathrm{~mL}$ of $150 \mathrm{mM}$ PBS in order to produce a final concentration of $10^{6}$ oocysts per $\mathrm{mL}$.

Because the dose distribution of UV irradiation delivered to oocysts in turbid water may vary according to the degree of movement of the water, experiments were performed under vigorously mixed and stationary conditions. Experiments were performed while varying the irradiation time and stirring conditions so as to produce either a completely mixed system or a completely stationary system. For UV irradiation of a completely mixed system, UV irradiation of low intensity $(0.10$ $\mathrm{mW} / \mathrm{cm}^{2}$ ) was applied for a long period of time (30-60 s) to a suspension that was being stirred vigorously with a magnetic stirrer. In experiments that were performed in a stationary system, turbid water containing $C$. parvum oocysts was vigorously stirred for $3 \mathrm{~min}$; immediately after the discontinuation of stirring, UV irradiation of high intensity $\left(1.00 \mathrm{~mW} / \mathrm{cm}^{2}\right)$ was applied for a short period of time (3-6 s).

Humin and kaoline are substances that adhere to the surface of $C$. parvum oocysts. Humic acid (Wako Co., Osaka, Japan) was dissolved in a small volume of $0.01 \mathrm{M}$ sodium hydroxide and diluted by 100 times. The dissolved humic acid solution was placed into three plastic tubes with an inner diameter of $36 \mathrm{~mm}$. In the first tube, a suspension of $C$. parvum oocysts was added. In this tube, oocysts coexisted uniformly with dissolved humin. In the second tube, the $\mathrm{pH}$ of the dissolved humic acid solution was adjusted to 6 with hydrochloric acid, and a suspension of $C$. parvum oocysts was then added. In this tube, oocysts coexisted uniformly with the particulate form of humin. In the third tube, a suspension of $C$. parvum oocysts was added and then the $\mathrm{pH}$ was adjusted to 6 with hydrochloric acid; the oocysts were incubated for one hour, allowing humin molecules to adhere to the surface of the oocysts.

Kaoline (Wako Co., Osaka, Japan) was dispersed in $150 \mathrm{mM}$ PBS and this solution was divided into two tubes with an inner diameter of $36 \mathrm{~mm}$. In the first tube, a suspension of C. parvum oocysts was added and sodium pyrophosphate was then added as a dispersant. In this tube, the oocysts coexisted uniformly with kaoline. In the second tube, a suspension of $C$. parvum oocysts was added and this was incubated for one hour, allowing kaoline molecules to adhere to the surface of the oocysts.

The tubes containing C. parvum oocysts and the various substances were placed under a $5 \mathrm{~W}$ low-pressure mercury lamp (QCGL5W-14 97D; Iwasaki Electronic, Co., Ltd., Tokyo, Japan). The intensity of the UV irradiation at a wavelength of $254 \mathrm{~nm}$ was measured by a UV dose rate meter (UIT-150-A; Ushio INC., Tokyo, Japan). The UV irradiation dose was altered by controlling the exposure time using an electrical shutter.

\section{Infectivity}

Infectivity was determined in animal infectivity tests with SCID mice maintained in a specific pathogen-free area at the Research Institute of Biosciences, Azabu University. This study was approved by the Animal Research Committee of Azabu University. Five-week-old SCID mice were used in the experiments after a one-week period of conditioning for adaptation to the new cage. Mice were individually housed in cages and were given autoclave-sterilized food and water. Four to five mice were used per dilution. Five-fold serial dilutions of $C$. parvum suspensions containing various substances were made using sterilized tap water. A $0.5-\mathrm{mL}$ aliquot was administered orally to each mouse. Mouse mortality at the early stages of the experiments was 2 out of 410 mice; no 
mice died beyond one week after oral administration. Four weeks after oral administration, fresh feces were collected, suspended in $50 \mathrm{~mL}$ of purified water and emulsified using a vortex mixer. A 5 -mL portion of this suspension was overlaid on $8 \mathrm{~mL}$ of sucrose solution and centrifuged at 1,500 $\times g$ at $4{ }^{\circ} \mathrm{C}$ for 15 minutes. The interface was recovered, and approximately $1 \mathrm{~mL}$ of the supernatant was filtered through a $25 \mathrm{~mm}$ cellulose acetate membrane disk filter (pore size, 0.8 micron). The filter was then stained using immunofluorescent antibodies against oocyst wall protein (Hydrofluoro Combo Kit, Strategic Diagnostics Inc., Newark, Del., USA) and was observed under an epi-fluorescent, differential contrast microscope (BX-60, Olympus, Tokyo, Japan) at a magnification of $400 \times$ in order to determine the presence or absence of oocysts. The most probable number (MPN) of infection was calculated from oocyst-positive mice, using the MPN program developed by Hurley and Roscoe (1983). The relative infectivity (Ir) of each sample was calculated by equation (1):

$$
I r=\frac{\mathrm{MPN}_{\mathrm{a}}}{\mathrm{MPN}_{0}}
$$

where $\mathrm{MPN}_{\mathrm{a}}$ is the most probable number of oocysts after UV irradiation, and $\mathrm{MPN}_{0}$ is the most probable number of oocysts before UV irradiation.

\section{In vitro excystation}

The viability of the $C$. parvum oocysts was determined by a modification of Woodmansee's method (Woodmansee, 1987). The original excystation protocol was slightly modified by the addition of a 5 minute preincubation in acidified Hank's balanced salt solution $(\mathrm{pH} 2.75)$ at $37{ }^{\circ} \mathrm{C}$ prior to incubation for excystation. After the preincubation, oocysts were incubated in excystation medium containing $1.5 \%(\mathrm{w} / \mathrm{v})$ taurocholic acid and $0.5 \%(\mathrm{w} / \mathrm{v})$ trypsin at $37^{\circ} \mathrm{C}$ for 60 minutes. The numbers of intact oocysts (IO) before excystation treatment, partially excysted oocysts (PO), empty oocysts (EO) and free sporozoites (S) were enumerated under a phase-contrast microscope at a magnification of $400 \times$. The excystation rate (V) was calculated by equation (2):

$$
\mathrm{V}(\%)=\frac{\mathrm{S} / 4}{\mathrm{IO}+\mathrm{PO}+\mathrm{EO}}
$$

The survival ratio $\left(S_{r}\right)$ was calculated from equation (3):

$$
S_{r}=\frac{\mathrm{V}_{\mathrm{a}}}{\mathrm{V}_{0}}
$$

Where, $\mathrm{V}_{\mathrm{a}}$ is the excystation rate of the UV-irradiated sample and $\mathrm{V}_{0}$ is the excystation rate of the control sample that was not subjected to UV irradiation.

\section{RESULTS AND DISCUSSION}

\section{Effects of various substances on $\mathrm{UV}$ inactivation of $C$. parvum oocysts}

If it is assumed that the UV intensity in a $C$. parvum oocyst suspension containing turbid substances decreases according to Lambert-Beer's law, the UV intensity $\left[I x\left(\mathrm{~mW} / \mathrm{cm}^{2}\right)\right]$ at a given depth $[x$ (cm)] would be calculated by equation (4):

$$
I x=I_{0} \exp (-A x)
$$

where, $I_{0}$ is the UV intensity at the surface of the suspension $\left(\mathrm{mW} / \mathrm{cm}^{2}\right)$ and $A$ is the absorption coefficient of the suspension at a wavelength of $254 \mathrm{~nm}\left(\mathrm{~cm}^{-1}\right)$. The average intensity of UV irradiation from the surface to the bottom of the suspension $\left[\operatorname{Iav}\left(\mathrm{mW} / \mathrm{cm}^{2}\right)\right]$ is given by equation (5): 


$$
\operatorname{Iav}=\frac{1}{R} \int_{0}^{R} I x d x=\frac{1}{R} \int_{0}^{R} I_{0} \exp (-A x) d x
$$

where, $I x$ is the UV intensity $\left(\mathrm{mW} / \mathrm{cm}^{2}\right)$ at a given depth $[x(\mathrm{~cm})]$ and $R$ is the thickness of the suspension $(\mathrm{cm})$. The average UV irradiation dose $\left[D x\left(\mathrm{~mJ} / \mathrm{cm}^{2}\right)\right]$ is therefore given by equation (6):

$$
D x=I a v \cdot t=\frac{t}{R} \int_{0}^{R} I_{0} \exp (-A x) d x
$$

where, $t$ is irradiation time ( $\mathrm{s}$ ).

Figure 1 shows a graph of the average dose of UV irradiation from the surface to the bottom of the suspension versus the relative infectivity of $C$. parvum oocysts (Run No. 1 to 6). The kinetic inactivation rate in turbid water was $4.058 \mathrm{~cm}^{2} / \mathrm{mJ}$, which was only $15 \%$ less than the kinetic inactivation rate in pure water $\left(4.690 \mathrm{~cm}^{2} / \mathrm{mJ}\right)$. Based on this result, the effectiveness of UV irradiation in inactivating C. parvum oocysts in turbid water can be calculated by the following procedure. First, the average UV dose was calculated using equation (6) while considering the reduction in UV intensity in the suspension, and the obtained average UV dose was then applied to the relationship between the UV dose and relative infectivity in pure water.

The average relative infectivity (Irav) in the completely stationary system was calculated by integrating the relative infectivity $(\operatorname{Irx})$ at a given depth $[x(\mathrm{~cm})]$ from the surface to the bottom of a suspension from equation (7):

$$
\operatorname{Ir} a v=\frac{1}{R} \int_{0}^{R} \operatorname{Ir} x d x
$$

where $R$ is the thickness of the suspension $(\mathrm{cm})$. The relationship between the relative infectivity (Irx) at a given depth $[x(\mathrm{~cm})]$ and the UV irradiation dose $\left[D x\left(\mathrm{~mJ} / \mathrm{cm}^{2}\right)\right]$ is assumed to be given by equation (8), which was derived from the results of experiments performed in pure water:

$$
\text { Irx }=\mathrm{e}^{-4.690 D x}
$$

Figure 2 shows the average UV irradiation dose, which was calculated from equation (6), versus the relative infectivity, which was calculated from equation (7). When the turbidity was $190 \mathrm{ntu}$ and the depth of the suspension was $30 \mathrm{~mm}$, the degree of UV beam penetration to the bottom of the suspension was expected to be less than $7 \%$.
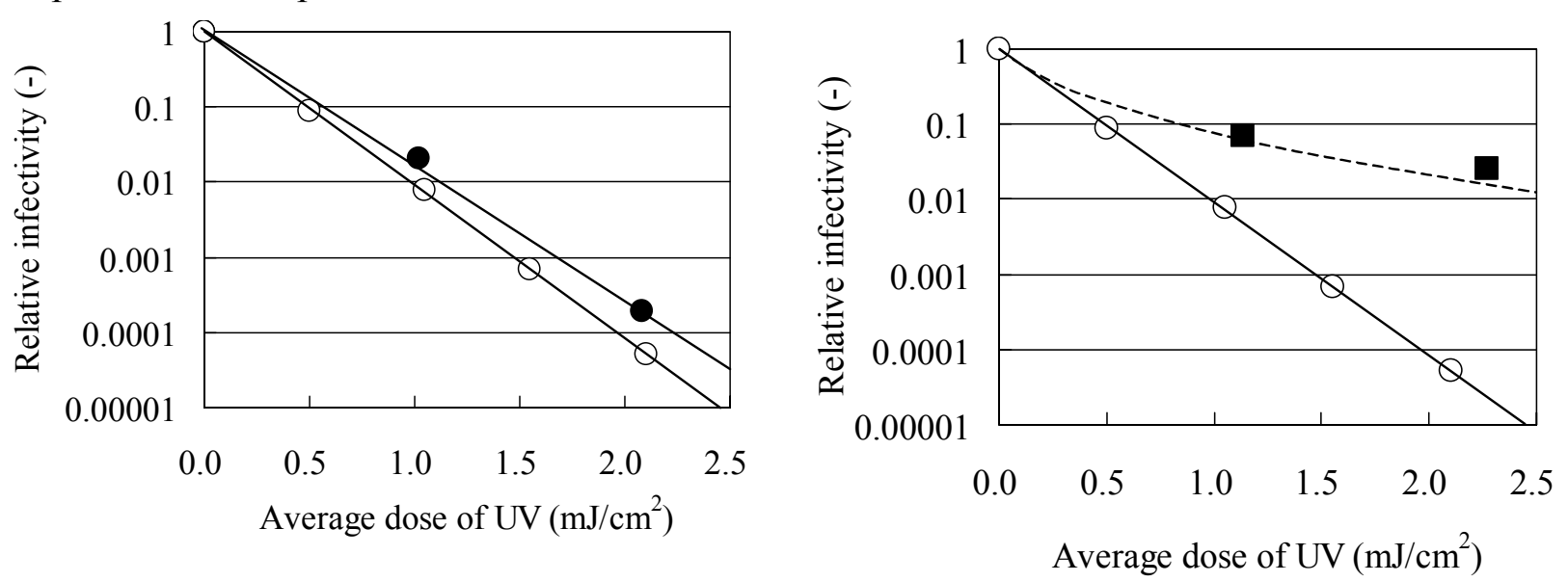

Figure 1. Plot of the observed relative infectivity of $C$. parvum oocysts versus the estimated average UV dose from the surface to the bottom of the oocyst suspension in the mixed system.

Symbols: $\_$, pure water (observed); , 190 ntu (observed).

Figure 2. Plot of the observed or calculated relative infectivity of $C$. parvum oocysts versus the estimated average UV dose in the stationary system.

Symbols: $\bigcirc$, pure water (observed);

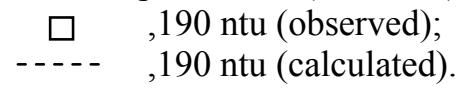


The estimated relative infectivity under such conditions markedly differed from that obtained in the equation expressing the relationship between UV irradiation dose and relative infectivity in pure water. The relative infectivity obtained in animal experiments (Run No. 1 to 4 and 7,8) were nearly in agreement with those calculated using equation (7). It therefore appears that the effectiveness of UV irradiation in inactivating $C$. parvum oocysts in a stationary system can be calculated using equation (7).

\section{Effect of adherent substances}

Humin was mixed with suspensions of $C$. parvum oocysts by three different methods, and UV irradiation was applied. The $\log _{10}$ inactivation of $C$. parvum oocysts in excystation and animal infectivity upon UV irradiation is shown in Figures 3 and 4. In C. parvum oocysts in pure water, UV irradiation at an average dose of $230 \mathrm{~mJ} / \mathrm{cm}^{2}$ achieved $1.91 \log _{10}$ inactivation of C. parvum oocysts in the in vitro excystation assay, and UV irradiation at an average dose of $1.50 \mathrm{~mJ} / \mathrm{cm}^{2}$ achieved $2.97 \log _{10}$ inactivation in the mouse infectivity assay. Upon application of the respective UV doses to C. parvum oocyst suspensions containing dissolved humin, UV irradiation achieved similar levels of oocyst inactivation (1.98 $\log _{10}$ and $2.99 \log _{10}$, respectively). Adhesion of humin particles to the oocyst wall tended to reduce the degree of inactivation. However, the magnitude of the $\log _{10}$ inactivation in suspensions containing humin particles was only approximately $20 \%$ less than that in pure water.

Our results indicate that for inactivation of $C$. parvum oocysts, the effectiveness of UV irradiation per unit dose in oocyst suspensions containing humin homogeneously mixed with oocysts was nearly as high as that in oocyst suspensions in pure water. This indicates that even though the UV beam passed through a turbid fluid, the effectiveness of the UV irradiation per unit dose remained unaltered. Our results also suggest that adhesion of humin to the oocyst wall had no marked shielding effect.

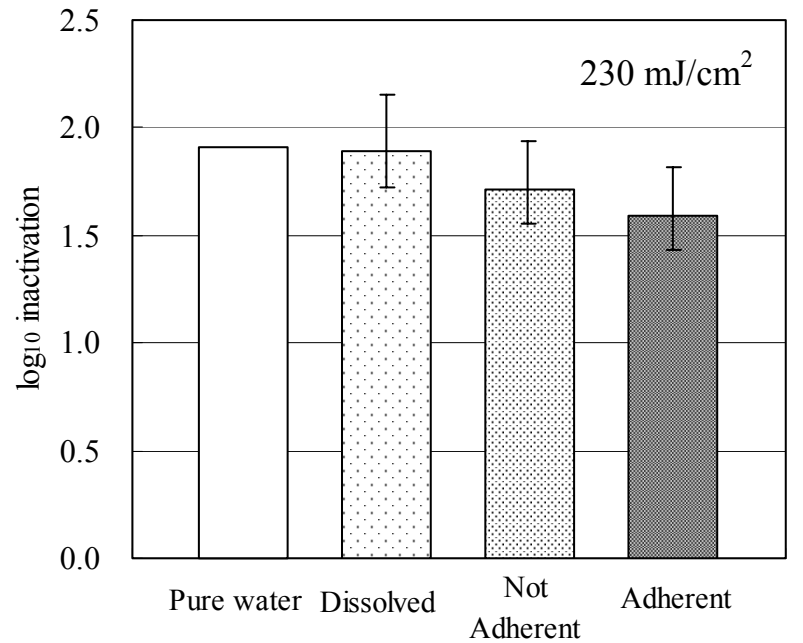

Figure 3. The $\log _{10}$ inactivation of $C$. parvum oocysts in excystation upon UV irradiation in the presence of humin. Bars indicate the means from two independent experiments, and the lines indicate the maximum and minimum values.

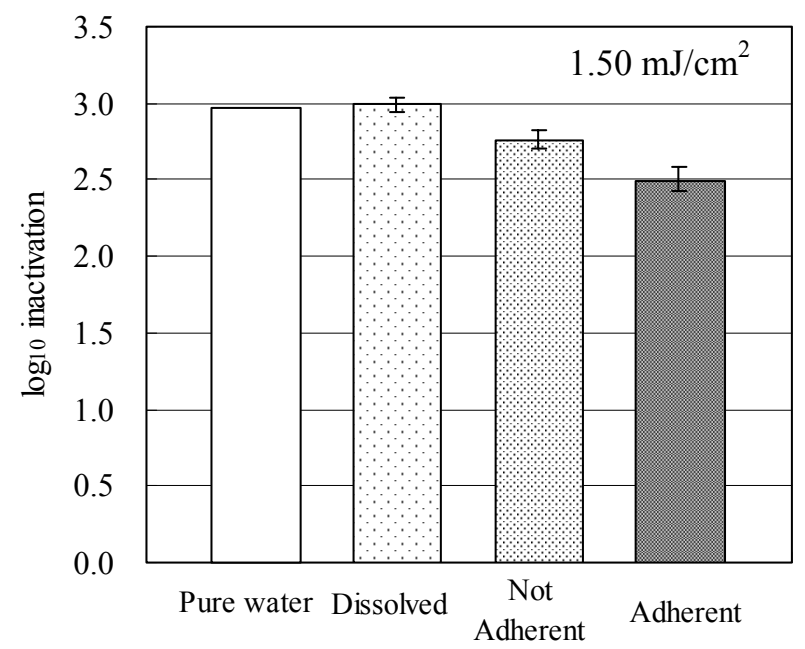

Figure 4. The $\log _{10}$ inactivation of $C$. parvum oocysts in animal infectivity upon UV irradiation in the presence of humin. Bars indicate the means from two independent experiments, and the lines indicate the maximum and minimum values.

Kaoline was mixed with $C$. parvum oocysts suspensions using two different methods. The $\log _{10}$ inactivation of $C$. parvum oocysts in excystation and animal infectivity that were subjected to UV irradiation in the presence of kaoline is shown in Figures 5 and 6. In experiments on mixtures of $C$. parvum oocysts and kaoline in which kaoline did not adhere to the oocyst wall, UV irradiation was 
slightly more potent in $C$. parvum oocyst suspensions in water containing kaoline $\left(1.99 \log _{10}\right.$ inactivation in the excystation assay and $3.18 \log _{10}$ inactivation in the animal infectivity assay) than in oocyst suspensions in pure water. However, because the increase in potency was negligible, we did not study whether this increase resulted from scattering of the UV beam by kaoline particles. In experiments on mixtures of $C$. parvum oocysts and kaoline in which kaoline adhered to the oocyst wall, the level of UV inactivation of $C$. parvum oocysts tended to be reduced, as was seen with adhesion of humin. However, the magnitude of the $\log _{10}$ inactivation with adhesion of kaoline was only approximately $10 \%$ less than that in pure water, irrespective of whether assessment was performed by excystation assay or by animal infectivity assay. These results suggest that the presence of adherent substances reduces the magnitude of the UV-induced $\log _{10}$ inactivation of $C$. parvum oocysts by $20 \%$ or less, regardless of whether the substance is dispersed in water or partly adhered to the oocyst wall.

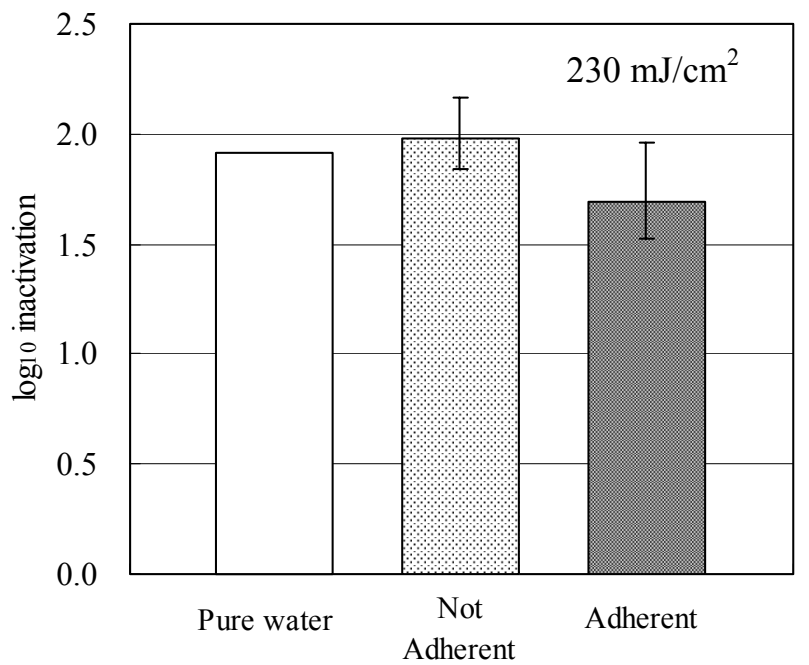

Figure 5. The $\log _{10}$ inactivation of C. parvum oocysts in excystation upon UV irradiation in the presence of kaoline. Bars indicate the means from two independent experiments, and the lines indicate the maximum and minimum values.

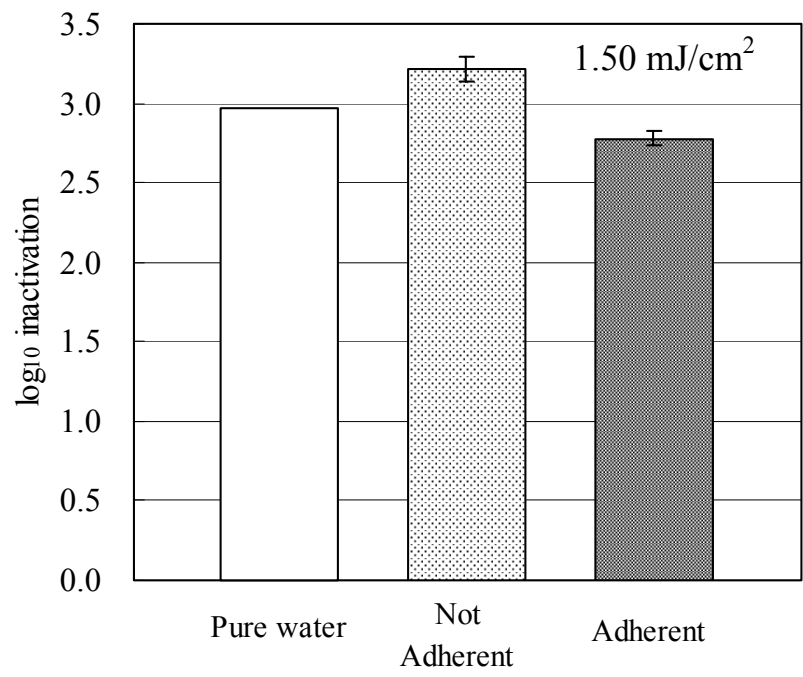

Figure 6. The $\log _{10}$ inactivation of C. parvum oocysts in animal infectivity upon UV irradiation in the presence of kaoline. Bars indicate the means from two independent experiments, and the lines indicate the maximum and minimum values.

\section{Conclusions}

The results of the present study can be summarized as follows:

(1) Although the dose of UV delivered to oocysts decreases due to the influence of turbid substances, the degree of expected inactivation can be estimated when the dose of UV delivered to oocysts is known.

(2) Humin and kaoline each reduced the magnitude of the UV-induced $\log _{10}$ inactivation of $C$. parvum oocysts by $20 \%$ or less, regardless of whether the substance was dispersed in the water or partially adhered to the oocyst wall.

\section{Acknowledgments}

This study was supported by the $2001^{\text {st }}$ to $2003^{\text {rd }}$ Grant-in-Aid for Scientific Research (B)(2) No.13450217 and $2002^{\text {nd }}$ to $2003^{\text {rd }}$ Grant-in-Aid for Scientific Research (C)(2) No.14550549 of the Ministry of Education, Science, Sports and Culture, Japan.

\section{References}

Atherton, F., Newman, C. and Casemore, D. (1995) An outbreak of waterborne cryptosporidiosis associated with a water supply in UK. Epidemiology and Infection, 115, 123-131. 
Baudin I. and Laine J. M. (1998) Assessment and optimization of clarification process for Cryptosporidium removal. Proc. AWWA WQTC.

Clancy J. L., Bukhari Z., Hargy T. M., Bolton J. R., Dussert W. and Marshall M. M. (2000) Using UV to inactivate Cryptosporidium. J. AWWA, 92, 97-104.

Gyurek, L. L., Finch, G. R. and Belosevic, M. (1997). Modeling chlorine inactivation of Cryptosporidium parvum oocysts. J. Environ. Eng., 9, 865-875.

Hashimoto A., Kunikane S. and Hirata T. (2002) Prevalence of Cryptosporidium oocysts and Giardia cysts in the drinking water supply in Japan. Wat. Res., 36, 519-526.

Hirata T., Chikuma D., Shimura A., Hashimoto A., Motoyama N., Takahashi K., Moniwa T., Kaneko M., Saito S. and Maede S. (2000) Effects of ozonation and chlorination on viability and infectivity of Cryptosporidium parvum oocysts. Wat. Sci. Technol., 41, 39-46.

Hirata T., Morita S., Sugimoto H., Takizawa H. and Endo T. (2002) Efficacy of low-pressure ultraviolet irradiation for inactivating Cryptosporidium parvum oocysts in turbid water. Cong. Int. Ultraviolet Assoc., Singapore.

Hurley, M. and Roscoe, M. E. (1983). Automated statistical analysis of microbial enumeration by dilution series. $J$. Appl. Bacteriol., 55, 159-164.

Korich D. G., Mead J. R., Madore M. S., Sinclair N. A. and Stering C. R. (1990) Effects of ozone, chlorine dioxide, chlorine, and monochloramine on Cryptosporidium parvum oocysts viability. Appl. Environ. Microbiol., 56, 1423-1428.

LeChevallier M. W., Norton W. D. and Lee R. G. (1991) Occurrence of Giardia and Cryptosporidium spp. in surface water supplies. Appl. Environ. Microbiol., 57, 2610-2616.

Linden K. G., Shin G-A and Sobsey M. D. (2000) Comparison of monochromatic and polychromatic UV light for disinfection efficacy. Proc. AWWA WQTC, 1274-1280.

Mackenzie W. R., Hoxie N. J., Proctor M. R., Stephen Gradus M., Blair K. A., Peterson D. E., Kazmierczak J. J., Addiss D. G., Fox K. R., Rose J. B. and Davis J. P. (1994) A massive outbreak in Milwaukee of Cryptosporidium infection transmitted through the public water supply, New Eng. J. Med., 331, 161-167.

Morita S., Namikoshi A., Hirata T., Oguma K., Katayama H., Ohgaki S., Motoyama N. and Fujiwara M. (2002) Efficacy of UV irradiation in inactivating Cryptosporidium parvum oocysts. Appl. Environ. Microbiol., 68, 5387-5393.

Nieminski E. C. and Ongerth J. E. (1995) Removing Giardia and Cryptosporidium by conventional treatment and direct filtration. J. $A W W A$, Sep., 96-106.

Ransome M. E., Whitmore T. N. and Carrington E. G. (1993) Effects of disinfectants on the viability of Cryptosporidium parvum. Wat. Suppl., 11, 75-89.

Rose J. B., Gerba C. P. and Jakubowski W. (1991) Survey of potable water supplies for Cryptosporidium and Giardia. Environ. Sci. Technol., 25, 1393-1400.

Shin G. A., Linden K.G., Arrowood M. J. and Sobsey M. D. (2001) Low-pressure UV inactivation and DNA repair potential of Cryptosporidium parvum oocysts. Appl. Environ. Microbiol., 67, 3029-3032.

Sobsey M. D. (1989) Inactivation of healthrelated microorganisms in water by disinfection process. Wat. Sci. Technol., 21, 179-195.

Woodmansee D. B. (1987) Studies of in vitro excystation of Cryptosporidium parvum from calves. J. Protozool., 34, 398-402.

Zimmer J. L., Slawson R. M. and Huck P. M. (2003) Inactivation and potential repair of Cryptosporidium parvum following low- and medium-pressure ultraviolet irradiation. Wat. Res., 37, 3517-3523.

Yamamoto, N., Urabe, K., Takaoka, M., Nakazawa, K., Gotoh, A., Haga, M., Fuchigami, H., Kimata, I .and Iseki, M. (2000) Outbreak of cryptosporidiosis after contamination of the public water supply in Saitama prefecture, Japan, in 1996. J. Japanese Associ. for Infect. Disease. 74, 518-526. 